\title{
- NOTAS-
}

\section{SECCION BIBLIOGRAFICA}

\section{LA PUBLTCACION DE LAA FLORA DE NUEVA GRANADA EN ESPAÑA}

En algún número anterior de esta Revista hicimos notar cuán conveniente sería para Colombia reclamar del Gobierno español el Archivo de la Expedición Botánica para publicarlo en Colombia, y agregábamos que gracias a los esfuerzos de nuestro académico honorario, don José Cuatrecasas, esa publicación se había iniciado en Madrid, pero que debido a la guerra actual que azota a la Península, tal obra corría peligro de suspenderse indefinidamente. En estas circunstancias era natural pedir a nuestro Gobierno el continuar la empresa tan felizmente iniciada por Cuatrecasas e interrumpida por la revolución. Pero hoy, sorprendidos por la grata noticia de que ella se continúa, a pesar de todo, en la Madre Patria, no podemos menos que felicitarnos a causa de tan excelente resultado, haciendo votos por que nuestro colega pueda corouar su labor con brillo para toda la Ciencia hispano-americana.

A continuación reproducimos lo escrito por don José Cuatrecasas con motivo de la publicación de la parte de la "Flora de Nueva Granada" que se refiere a la Quinologia de Mutis. Dice así:

"En 1783, a propuesta del Virrey don Antonio Caballero y Góngora, y por orden de Carlos III, se creaba la Expedición Botánica del Nuevo Reino de Granada. Fue nombrado director de la misma el sabio naturalista gaditano José Celestino Mutis, antiguo discípulo de Barnades en el Jardín Botánico de Migas Calientes y que ya desde 1761 se encontraba en Bogotá ejerciendo la medicina. Este hombre, que habia demostrado sus grandes dotes de maestro y de investigador, practicando la enseñanza de varias ciencias, observador minucioso, organizador activo y eficaz, no defraudó las esperanzas que en él se depositaron al encargarle la empresa por él fervientemente apetecida.

Ya la maravillosa flora de Nueva Granada contaría, como la del Perú y Chile, con hombres de temple y conocimientos, capaces de dar a conocer al mundo la riqueza y las novedades científicas de tales países. $\mathrm{Y}$ en efecto, instalado Mutis en la ciudad de Mariquita, junto al río Magdalena, entre las imponentes cordilleras Oriental y Central de Colombia, creó una verdadera escuela de fitógrafos y dibujantes que escudriñaron valles, barrancos y montañas desde la selva tropical del río, hasta las más altas cimas de los Andes. Aquí estuvo siete años. En 1790 se trasladó a Bogotá, donde él y sus colaboradores pudieron continuar su labor, completando los trabajos empezados en Mariquita, y dedicarse a la exploración de las partes más elevadas de la Cordillera Oriental.

El resultado de todos estos trabajos es apenas conocido. otros sabios exploradores españoles, Ruiz, Pavón, Sessé y Mociño, publicaron una parte de sus estudios sobre la flora del Perú, Chile y México, publicaciones que les han proporcionado universal y positivo renombre. In cambio, la labor de 25 años de la Expedición Botánica del Nuevo Reino de Granada se supone casi nula por desconocida, pues sólo se suele saber de ella por las referencias someras que algunos autores han dado de la obra inédita de Mutis. No obstante, es la que más se admira cuando se considera cómo pudo Mutis organizar toda una escuela de más de veinte hombres metódicamente dedicados a la producción científica. Ya muerto Mutis, y durante la guerra de la independencia, debió de perderse una parte de su obra, tal vez el manuscrito de la famosa Flora. Lo cierto es que actualmente sólo se conservan las ilustraciones de la monumental Flora de Nueva Granada. Son 2.500 láminas en negro y 4.170 láminas en color y en gran folio, que representan plantas enteras o partes de plantas, y son una maravilla de disposición artística así como de ejecución e interpretación rigurosamente científica del natural. De entre los 43 volúmenes en que están distribuídas estas láminas, destaca el correspondiente al estudio de las Quinas, en cuyo descubrimiento y en el estudio de cuyas propiedades y usos terapéuticos, tomó una activísima participación Mutis. Este es el único volumen que lleva texto primorosamente manuscrito, en el que se describen las cortezas, sus propiedades, aplicaciones, formas farmacéuticas, con copiosa aportación de datos, experiencias e ideas propias sobre la acción de las diversas quinas y modo de emplearlas; y se clasifican y describen las siete especies y numerosas variedades que se representan en 61 láminas.

El texto ya había sido publicado en su mayor parte, por varios autores, en fragmentos, siendo la mejor edición la de Hernández de Gregorio (1828), incompleta por faltarle la parte sistemática. El hecho de haberse dado al público de una manera tan fragmentaria y desprovista de la documentación ilustrada, la obra de Mutis, es la causa de que no sea considerada en lo que vale por algunos autores. Abona este criterio el que Humboldt fue un defensor suyo, porque 1o conoció en Bogotá y pudo apreciar con sus propios ojos la elevada calidad de su trabajo riguroso, pausado y constante. ISn 1808 fallecía Mutis. El año siguiente prologaba su "Historia de los Arboles de la Quina" el continuador de la Expedición, su sobrino Sinforoso Mutis, $y$ la dejaba lista para ser publicada. Numerosas vicisitudes han pasado desde entonces que han impedido la publicación de la Flora de Nueva Granada, no superada ni igualada por otra obra de su género; es evidente, sin embargo, que la causa principal ha sido la desidia de nuestros dirigentes políticos que se sucedieron desde aquella fecha.

En 1638, la Virreina del Perú, doña Francisca Enriquez de Rivera, condesa de Chinchón, que dio nombre a los árboles de la quina, padeciendo tercianas, fue felizmente tratada con polvos de corteza del árbol de Loja, suministrados por indígenas, hecho inicial del conocimiento científico de la acción terapéutica de la quina.

En 1738, La Condamine daba a conocer al mundo la primera descripción del árbol de la quina.

En 1938, en plena guerra, a los tres siglos del primer hecho citado $\mathrm{y}$ a los dos siglos del segundo, el Ministerio de Instrucción Pública y Sanidad edita en España la "Historia de los Arboles de la Quina" de José Celestino Mutis; 104 páginas de manuscrito y 61 láminas a gran folio y todo color, edición facsímil del primoroso volumen original fechado por Sinforoso en 1809.

Por fin, en justicia a Mutis y a la escuela que personifica, escuela de científicos revolucionarios, que lucharon ardorosamente por la libertad, y para honor de quienes rigen hoy los destinos de la República, la publicación de la Flora de Nueva Granada de Mutis, es hoy un hecho, que nos enaltece $y$ nos vindica.

José Cuatrecasas".

\section{EXPLICACION DE CALDAS REFERENTE A LA
LAPIDA DE CUENCA}

"Todos saben que los señores Académicos terminaron sus trabajos de la medida del grado contiguo al ecuador en la llanura de Tarqui; que midieron una segunda base semejante a la de Yaruquí, y que el observatorio austral lo establecieron en una de las haciendas inmediatas. Entonces pertenecía ésta a un vecino de Cuenca llamado don N. Sempertegui. Aquí dejó M. de La Condamine una lápida de mármol blanco, de que abundan las inmediaciones. Pero los nuevos dueños que sucedieron a Sempertegui la arrancaron de su lugar y le dieron un destino bien diferente del que tuvo en su origen. En lugar de perpetuar la memoria y los resultados de unas observaciones que decidieron la figura de la tierra, que auguran la vida del hombre en Groenlandia y en el cabo de Van-Diemen, las más interesantes de que puede gloriarse la Astronomía, servia de puente sobre una acequia, cubierta de tierra y sepultada. Qué destino! Existe acaso algún genio enemigo de este viaje célebre? Todo perece, todo se arruina por los bárbaros. Qué tiempos tan diferentes los de 1740 y los de 1804 ! En esa época infeliz para las ciencias se creía buen ciudadano el que arruinaba, el que hacía perecer hasta las ruinas de los únicos monumentos que pueden honrar nuestra razón en la América Meridional. Por fortuna Córdoba, este sacerdote ilustrado de que tánto hemos hablado en nuestro viaje a Paute, vio esta lápida en el destino que acabamos de ver le habían dado los buenos vecinos de Cuenca; la hace lavar, lee, reconoce su importancia, copia la inscripción $\mathrm{y}$ hace dar al monumento un lugar más honroso. No se contenta con esto: manda una copia de la inseripción a los editores del Mercurio Peruano, la cual se publica. Pero mal entendida, se halla desfigurada en este periódico. Nosotros le hemos restituído su genuino sentido, copiándola con la mayor fidelidad.

En este estado se hallaban las cosas cuando llegué a Cuen. ca. Todo mi cuidado fue el averiguar por el paradero de esta lápida preciosa y por el destino que le habian dado esos bárbaros. El mismo Córdoba que la había copiado me suministró todas las noticias necesarias. La familia de Crespos, en Cuenca, tomó en arrendamiento la hacienda de Sempertegui. Cuando volvió al fundo, sacó, sin saber con qué derecho, esta lápida de su lugar y la transportó al Ingenio, pequeña quinta a una legua de Cuenca, en donde la hallé abandonada, con el destino de perforarla para que sirviese de rejilla a una acequia. Pensé en pedir amistosamente se restituyese esta alhaja a los astrónomos a quienes pertenecía; pensé también en representarlo al Gobierno a fin de que se libertase del destino que se le intentaba dar y se conservase; pero el conocimiento que he adquirido del carácter pleitista de estas gentes, que hacen un proceso por el ala de una mosca; el reflexionar sobre que nada avanzaba, aun vencido este pleito astronómico, pues volvía a quedar en 
Rev. Acad. Colomb. Cienc. Ex. Fis. Nat. 42(Suplemento):90-92, octubre de 2018

doi: http://dx.doi.org/10.18257/raccefyn.742

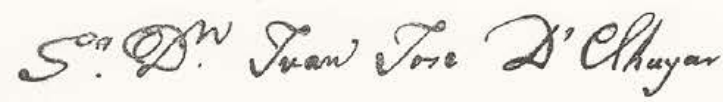

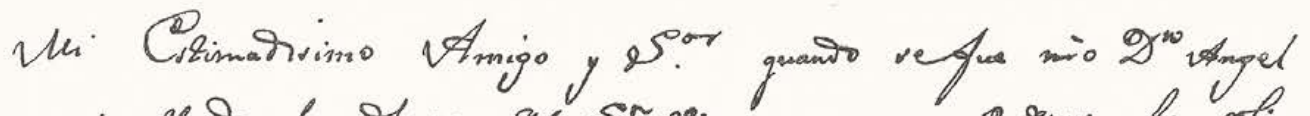

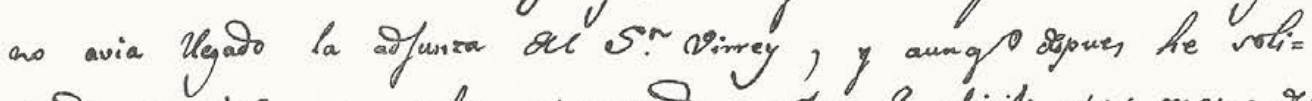

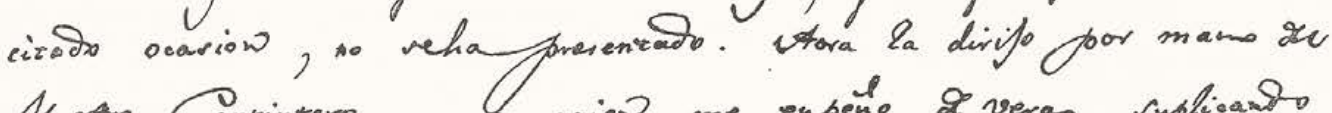

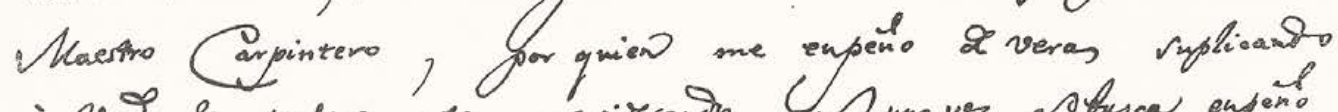

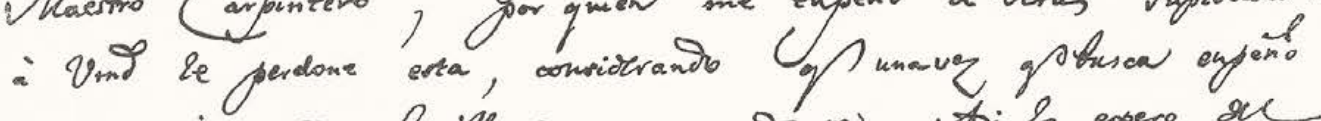

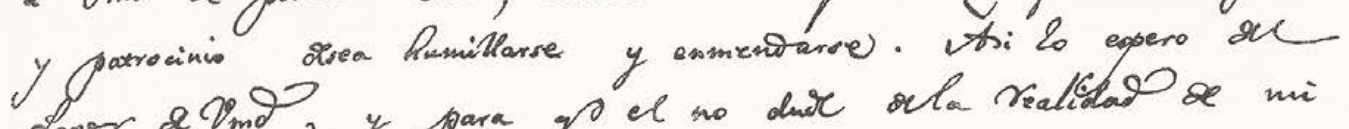

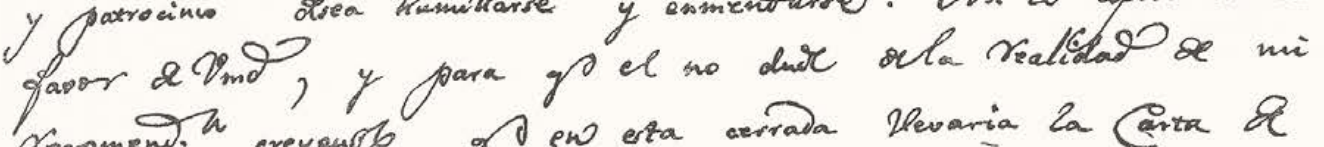

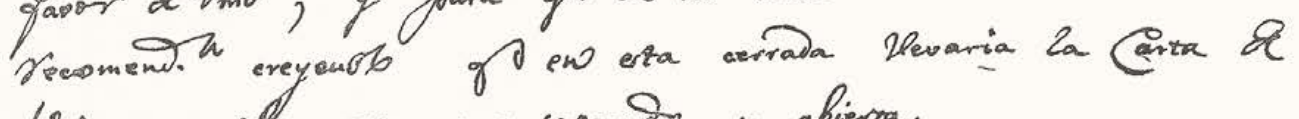
Urias, escribo orra por reparaino y abiersa.

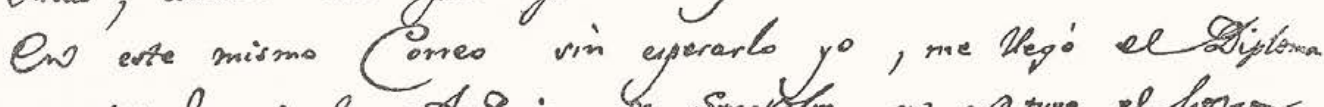

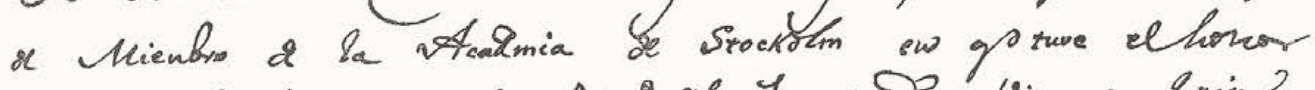

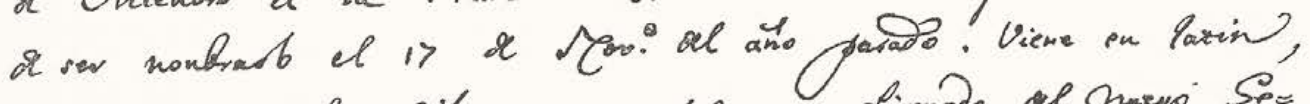

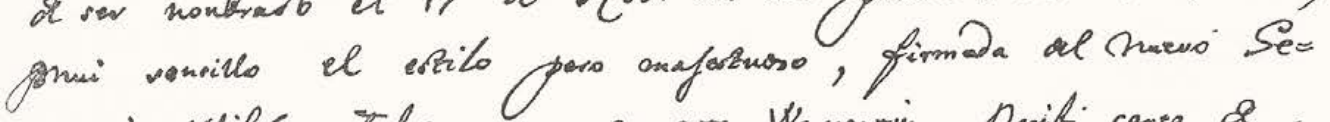

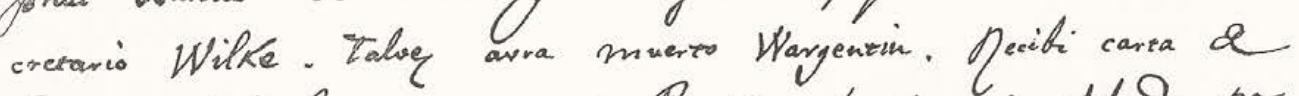

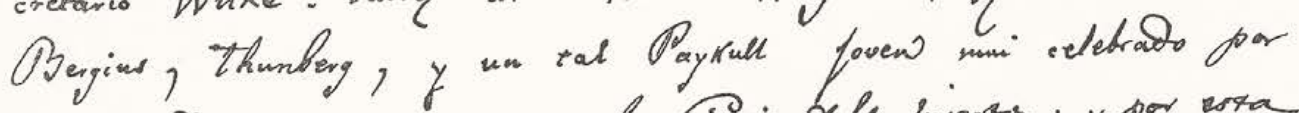

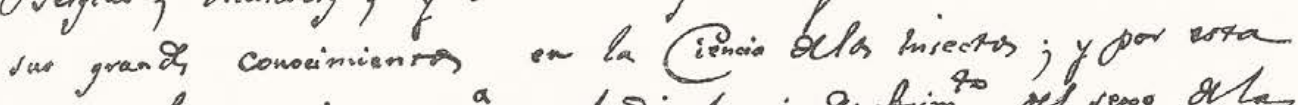

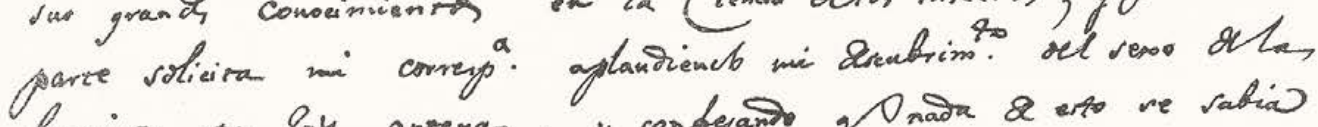

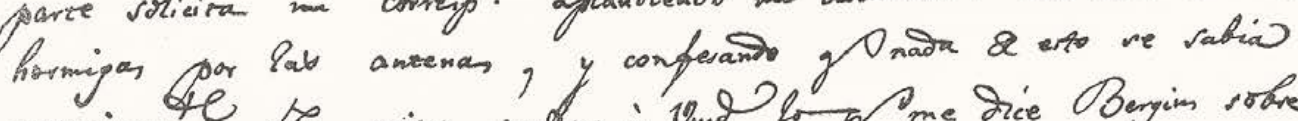

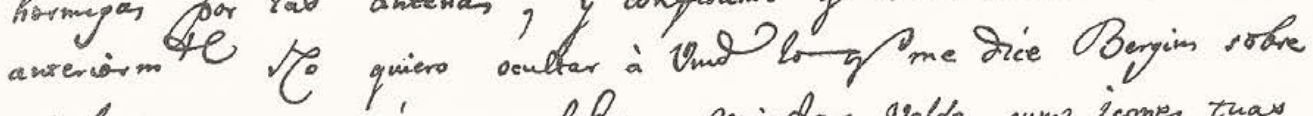

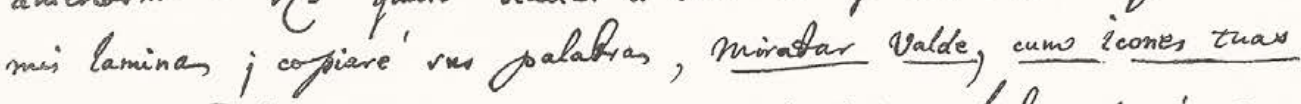

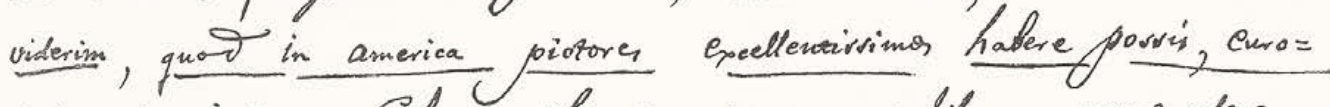
paiv Mugeriores. Saliva milic movetur amo hibumo quew edere

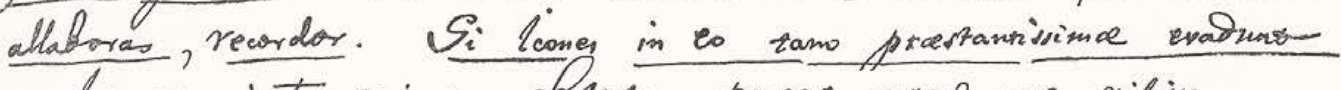

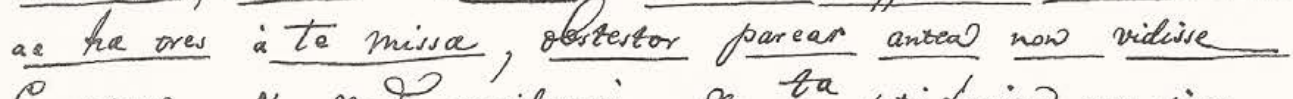

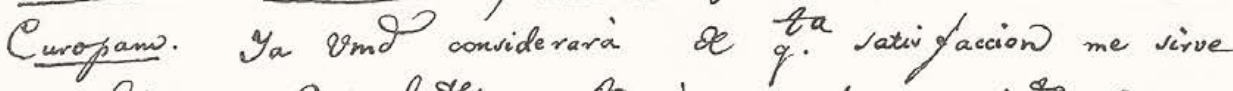

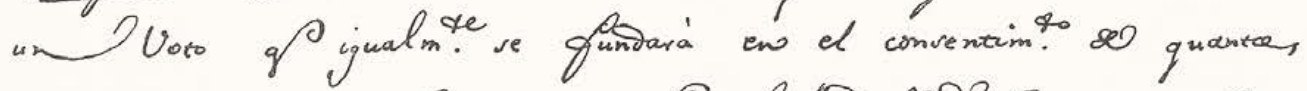

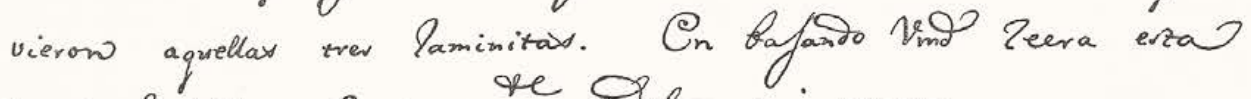
corrapondincial of seguram. Tenulla mis tarreas.

Nev aleyrare' go Void re mantenga bueno, y me mand con la reguridat de qp roy

Mariguita 3o de vifoseryss\} Sir afmo vtmigo O. S. Nurut 
unas manos poco ilustradas, $\mathrm{y}$ que a la vuelta de diez años se destinaría a usos miserables y bárbaros, me hizo tomar la determinación de apoderarme de ella y trasladarla a Bogotá.

"En el Mercurio Peruano de 1793 se publicó la inseripción con muchos errores; mas es a la letra como sigue:

HOC IN VALLIS TARQUENSIS ANFRACTU

ET IN IPSO VILLAE SEMPERTEGUIANAE FANO NONDUM CONSWCRATO

MERIDIANI ARC, GEOMETRI MENSURATI

EXTREMA IN PARTE AUSTR. SITO A TURRI TFMPLI MAJORIS CONCHENSIS

CCICCDL HEXAPEDAS PARISIENS. DISTANTE IN IINEA

AB AUSTRO AD OCC. DECL. GR. XVIII CUM MIN, XXX

OBSERVATAE VERTICE BOREAM VERSUS STELLARUM

IN MANU ANTINOI BAYERO $\theta$

GRAD. I MIN. XXX SIC. XXXIV TUM. XXVIIII (1).

Para verificar los resultados consignados en esta lápida, hice en Cuenca un número prodigioso de observaciones de

$\theta$ de Antinoo. Como la misma lápida nos enseña que la torre de la matriz de Cuenca dista del observatorio del Tarqui 10.550 toesas, y la dirección de la línea que unía estos puntos (de Sur hacia Occidente) $18^{\circ} 30^{\prime}$, puedo deducir la distancia al cenit de $\theta$ de Antinoo a Tarqui en 1804, y por consiguiente en 1742 .

\section{CARTA ORIGINAL DE MUTIS CUYO FACSIMULE SE} REPRODUCE IN LA PAGINA ANTERIOR

Señor don Juan José D'Elhuyar:

Mi estimadísimo amigo y señor:

Cuando se fue nuestro Don Angel no había llegado la adjunta del Señor Virrey, y aun cuando después he solicitado ocasión, no se ha presentado. Ahora la dirijo por mano del maestro carpintero, por quien me empeño de veras, suplicando a Ud. le perdone esta, considerando que una vez que busca empeño él y patrocinio, desea humillarse $\mathrm{y}$ en mendarse. Así lo espero del favor de Ud.; y para que él no dude de la realidad de mi recomendación creyendo que en ésta cerrada llevaría la carta de Orías, escribo otra por separado $y$ abierta.

En este mismo correo, sin esperarlo vo, me llegó el Diploma de miembro de la Academia de Estocolmo en que tuve el honor de ser nombrado el 17 de noviembre del año nasado. Viene en latín, muy sencillo el estilo pero majestuoso, firmado del nuevo Secretario Wilke. Tal vez habrá muerto Wargentin. Recibí carta de Bergius, Thunberg, y un tal Paykull, joven muy celebrado por sus grandes conocimientos en la Ciencia de los insectos; $y$ por esta parte solicita $\mathrm{mi}$ correspondencia, aplandiendo mi descubrimiento del sexo de las hormigas por las antenas, y confesando que nada de esto se sabia anteriormente. No quiero ocultar a Ud. lo que me dice Bergius sobre mis láminas; copiaré sus palabras: "Mirabar valde, cum icones tuas viderim, quod in America pictores excellentissimos habere possis, europoeis superio. res. Saliva mihi movetur cum librum quem edere allaboras, recordor. Si icones in eo tam prestantíssimae evadunt ac ha tres a te missae, obstetor parear antea non vidisse Europam". Ya Ud. considerará de cuánta satisfacción me sirve un voto que igualmente se fundará en el consentimiento de cuantos vieron aquellas tres laminitas. En bajando Ud. verá esta correspondencia que seguramente endulza mis tareas.

Me alegraré que Ud. se mantenga bueno, $y$ me mande con la seguridad de que soy su Affmo. amigo.

Mariquita 30 de agosto de 1785 .

J. C. Mutis. 